\title{
MACULAR ISCHAEMIA IN POSTERIOR UVEITIS
}

\author{
C. R. BENTLEY, M. R. STANFORD, J. S. SHILLING, M. D. SANDERS and E. M. GRAHAM \\ London
}

\begin{abstract}
SUMMARY
The commonest cause of visual morbidity in patients with posterior uveitis is cystoid macular oedema, which usually responds to immunosuppressive treatment. However, a small group of patients do not have a satisfactory visual outcome despite apparently adequate therapy. In a retrospective study of 345 angiograms of 135 patients with active non-occlusive retinal vasculitis 12 patients were identified by independent masked review as showing macular ischaemia on their fluorescein angiograms. Four patients had Behçet's disease, 4 sarcoidosis, and 4 idiopathic retinal vasculitis. Follow-up of these patients for an average of 36 months (range 6-120 months) showed that visual acuity failed to improve in 4 patients and dropped by an average of three lines Snellen in the other 8. We suggest that a poor visual outcome in some patients with posterior uveitis may be predicted by the presence of macular ischaemia on fluorescein angiography and that immunosuppressive therapy should be prescribed with caution in these patients.
\end{abstract}

The major cause of visual morbidity in patients with chronic posterior uveitis is cystoid macular oedema (CMO). The pathogenesis of this complication is unknown, but it is assumed to arise from localised breakdown of the blood-retinal barrier (BRB) secondary to inflammation. Macular oedema usually responds to treatment with systemic immunosuppression, particularly steroids and cyclosporin A. However, in all major treatment trials over the last 10 years a significant number of patients failed to improve despite full immunosuppressive treatment, suggesting that other irreversible factors are contributing to visual loss. ${ }^{1-9}$

In a series of 56 patients with sight-threatening intermediate or posterior uveitis, 14 of 31 with CMO did not improve on either cyclosporin A or prednisolone. ${ }^{1}$ This failure was attributed to persistent CMO shown on fluorescein angiography (FFA). Nine patients (15 eyes) with posterior uveitis of varying aetiology were treated with cyclosporin A; in 4 eyes the vision did not improve but the cause of this was not explained. ${ }^{2}$ In a series of 12 patients

Correspondence to: Mr. M. R. Stanford, FCOphth, Medical Eye Unit, St. Thomas' Hospital, Lambeth Palace Road, London SE1 7EH, UK. with severe Behçet's uveitis, 5 did not improve on cyclosporin A therapy, 2 being described as having severe ocular damage although the specific features on FFA were not described. ${ }^{3}$ Other recent studies on therapy for posterior uveitis have not analysed the reasons for visual failure either clinically or by FFA..$^{4-9}$

In some of our patients who failed to respond to full immunosuppressive treatment, we have observed macular ischaemia as an incidental finding. We therefore studied retrospectively a large population of patients with posterior uveitis to try and determine whether visual outcome could have been predicted from FFA.

\section{PATIENTS AND METHODS}

Three hundred and forty-five fundus fluorescein angiograms of 115 patients with active non-occlusive retinal vasculitis were examined. All patients were attending the Medical Eye Unit at St Thomas' Hospital. Thirty-four patients with possible macular ischaemia demonstrated in the early phase of the angiogram were identified. For the purposes of this study macular ischaemia was defined as closure of perifoveal capillaries identified by an enlarged and/or irregular foveal avascular zone.

This subgroup of 35 angiograms was then independently reviewed by three masked observers. Angiograms were discarded if there was evidence of cloudy media, vein occlusions, diabetic retinopathy or no agreement by the three independent observers. The patients' records were then examined to determine visual outcome and response to therapy. In particular, visual acuity at the time of the relevant FFA and at the end of the follow-up period was recorded. The results of investigations to exclude possible causes of intravascular coagulation were available in all cases. These included full blood count, erythrocyte sedimentation rate, protein electrophoresis, C-reactive protein, blood glucose, liver function tests, protein $\mathrm{C}$, protein $\mathrm{S}$, antithrombin III and fibrinogen levels.

\section{RESULTS}

Twelve patients were identified as having macular ischaemia on FFA. There were 5 males and 7 females, ranging in age from 19 to 55 years (mean 42 years). The clinical 
Table 1. Clinical features of .12 patients with posterior uveitis and macular ischaemia

\begin{tabular}{|c|c|c|c|c|c|c|c|c|c|}
\hline \multirow[b]{2}{*}{ Patient } & \multirow[b]{2}{*}{ Sex } & \multirow{2}{*}{$\begin{array}{l}\text { Age } \\
(\mathrm{yr})\end{array}$} & \multirow[b]{2}{*}{ Diagnosis } & \multicolumn{2}{|c|}{ Visual acuity: initial } & \multicolumn{2}{|c|}{ Visual acuity: final } & \multirow{2}{*}{$\begin{array}{l}\text { Immuno- } \\
\text { suppression }\end{array}$} & \multirow[b]{2}{*}{ Investigations } \\
\hline & & & & $\mathrm{R}$ & $\mathrm{L}$ & $\mathrm{R}$ & $\mathrm{L}$ & & \\
\hline 1 & $\mathrm{~F}$ & 39 & Sarcoid & $6 / 36^{a}$ & $6 / 60$ & $6 / 60^{a}$ & $\mathrm{CF}$ & Prednisolone and azathioprine & NAD \\
\hline 2 & M & 52 & Idiopathic & $6 / 12^{a}$ & $6 / 9$ & $6 / 12^{a}$ & $6 / 9$ & Prednisolone and CyA & NAD \\
\hline 3 & $\mathrm{~F}$ & 31 & Behçet's & $6 / 9$ & $6 / 24^{a}$ & $6 / 9$ & $6 / 60^{a}$ & Prednisolone and azathioprine & Raised antithrombin III \\
\hline 4 & $\mathbf{M}$ & 33 & Sarcoid & $6 / 12^{a}$ & $6 / 18$ & $\mathrm{HM}^{\mathrm{a}}$ & $6 / 60$ & $\begin{array}{l}\text { Prednisolone, azathioprine } \\
\text { and CyA }\end{array}$ & NAD \\
\hline 5 & $\mathrm{~F}$ & 19 & Idiopathic & $6 / 12^{\mathrm{a}}$ & $6 / 9$ & $6 / 24^{a}$ & $6 / 9$ & $\begin{array}{l}\text { Prednisolone, azathioprine } \\
\text { and CyA }\end{array}$ & NAD \\
\hline 6 & $\mathrm{~F}$ & 38 & Idiopathic & $6 / 24^{a}$ & $6 / 24$ & $6 / 60^{\mathrm{a}}$ & $6 / 36$ & Prednisolone and CyA & NAD \\
\hline 7 & M & 48 & Behçet's & $6 / 24^{a}$ & $6 / 9$ & $6 / 60^{a}$ & $6 / 18$ & Prednisolone and CyA & NAD \\
\hline 8 & $\mathrm{~F}$ & 33 & Behçet's & $6 / 24^{a}$ & $6 / 18$ & $6 / 24^{a}$ & $6 / 18$ & Prednisolone and CyA & NAD \\
\hline 9 & $\mathbf{M}$ & 45 & Behçet's & $\mathrm{CF}^{\mathrm{a}}$ & $6 / 5$ & $\mathrm{HM}^{\mathrm{a}}$ & $6 / 5$ & $\begin{array}{l}\text { Prednisolone, azathioprine } \\
\text { and CyA }\end{array}$ & NAD \\
\hline 10 & $\mathbf{M}$ & 43 & Sarcoid & $6 / 12$ & $6 / 12^{\mathrm{a}}$ & $6 / 9$ & $6 / 18^{a}$ & Prednisolone & Raised antithrombin III \\
\hline 11 & $\mathrm{~F}$ & 42 & Sarcoid & $6 / 5$ & $6 / 24^{a}$ & $6 / 5$ & $6 / 24^{a}$ & Prednisolone & NAD \\
\hline 12 & $\mathrm{~F}$ & 55 & Idiopathic & $6 / 12^{a}$ & $6 / 9$ & $6 / 12^{a}$ & $6 / 9$ & Prednisolone & NAD \\
\hline
\end{tabular}

F, female; M, male; R, right; L, left; CF, counting fingers; HM, hand movement; CyA, cyclosporin A; NAD, no abnormality demonstrable. ${ }^{a}$ Eye with ischaemic macula.

details of each patient, including treatment modalities, are shown in Table I. Four patients had sarcoidosis, 4 had Behçet's disease and 4 had idiopathic retinal vasculitis. It should be noted that in 3 patients vision also became worse in the other eye during follow-up. This was due to optic nerve infiltration (patient 4) cataract (patient 6) and a macular hole (patient 7).

The investigations for haematological and biochemical abnormalities were unrewarding, except in 2 patients ( 3 and 10) who had a mildly elevated antithrombin III level. Follow-up was for 6-120 months (mean 36 months). In 8 of the patients visual acuity dropped by an average of three lines Snellen. In the other 4 patients the acuity remained unchanged (Fig. 1). All patients were initially managed with prednisolone ( $80 \mathrm{mg}$ for 3 days, $60 \mathrm{mg}$ for 3 days, $40 \mathrm{mg}$ for 1 month and reducing thereafter). Severe steroid side effects, high relapse rate, or failure to control intraocular inflammation necessitated addition of either azathioprine and/or cyclosporin $\mathrm{A}$ in 9 patients.

\section{CASE HISTORIES}

Two examples of case histories are detailed.

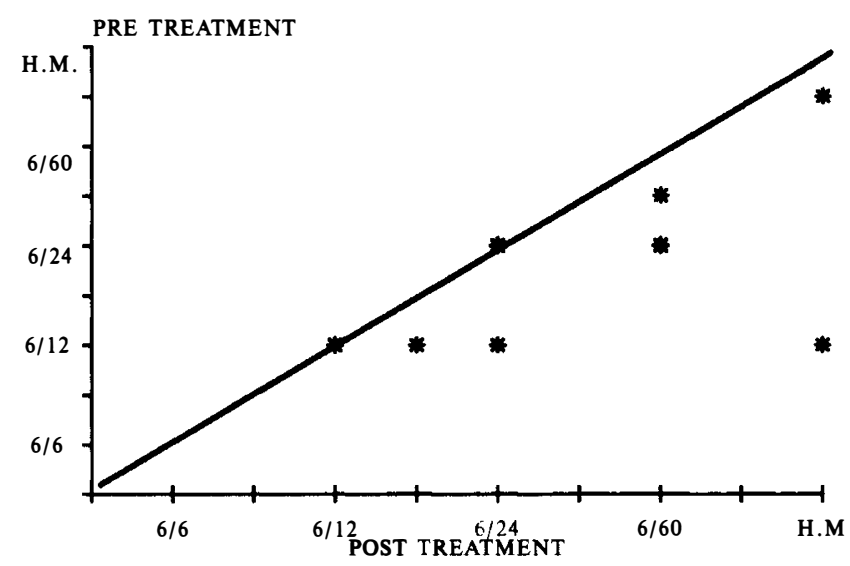

Fig. 1. A comparison of pre-and post-treatment visual acuity in patients with posterior uveitis and macular ischaemia. H.M., hand movement.

\section{Patient 3}

A 31-year-old woman was referred with a 4-year history of Behçet's disease associated with bilateral retinal vasculitis. Visual acuity in the affected left eye was 6/24 and decreased to $6 / 60$ despite extensive immunosuppression with prednisolone and azathioprine. FFA showed macular ischaemia with some diffuse microvascular leakage in the late films (Fig. 2). Further immunosuppression with cyclosporin A to improve the visual acuity was not recommended in this case.

\section{Patient 11}

A 42-year-old Mauritian woman presented with a 3-month history of blurred vision, mild photophobia and intermittent redness in the left eye. She also complained of cough, wheeze and a papular skin rash. Visual acuity in the left eye was 6/24. A left panuveitis was found with obvious CMO, but the FFA showed additional macular ischaemia (Fig. 3). A diagnosis of sarcoidosis was made from a skin biopsy. She was started on $40 \mathrm{mg}$ prednisolone. Her cough and skin rash immediately improved, but no improvement in visual acuity was seen after 6 weeks of therapy.

\section{DISCUSSION}

The results of this preliminary study have shown that in a small group of patients with posterior uveitis the failure of medical treatment to improve vision is due to the presence of macular ischaemia. The pattern of macular ischaemia could be detected in both active and quiet cases and was seen even in the presence of CMO. In all cases macular ischaemia was evident in the early venous phase of the angiogram, but because an accurate appraisal could only be made on clear angiograms it is probable that more cases with cloudy media had been rejected in the selection process. Previous therapeutic trials in posterior uveitis have reported variable success but the reasons for visual failure in these trials were not usually explained. In three recent studies approximately $50 \%$ of patients failed to improve 

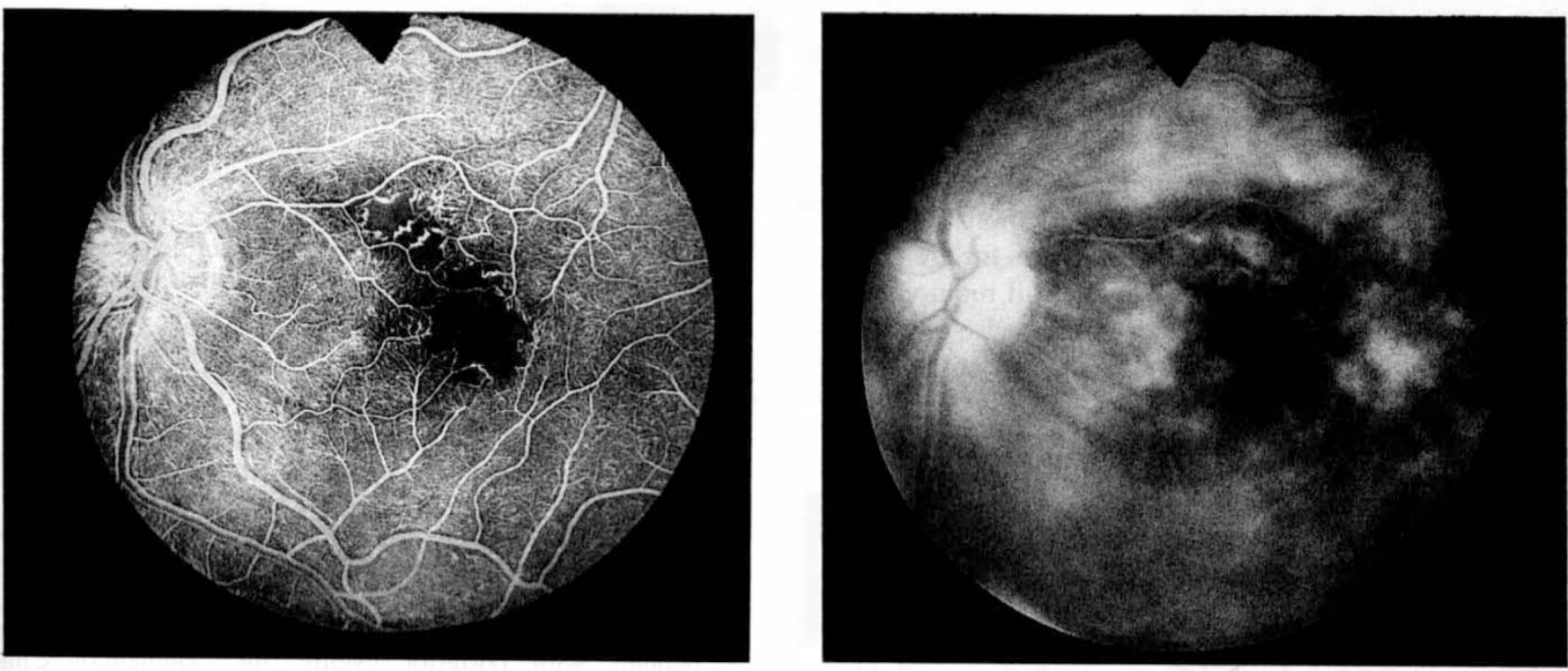

Fig. 2. Fluorescein angiogram of patient 3. Left: in the early phase, irregularity of the foveal avascular zone and perifoveal capillary drop-out. Right: in the late phase, diffuse microvascular leakage at the posterior pole but no cystoid macular oedema.

visually (i.e. more than one line Snellen), although success was reported in clearing the ocular media. ${ }^{1,2}$ In those cases where FFA was performed the reason for visual loss was thought to be persistent macular oedema. ${ }^{1-3}$ However, as the degree of retinal thickening was not commented on, it could not be determined, whether CMO caused the visual loss as it is well known that mild degrees of CMO are compatible with good visual acuity. ${ }^{10}$

The presence of macular ischaemia, unassociated with a predisposing systemic disease such as diabetes or local vaso-occlusive events, has not previously been reported in patients with posterior uveitis. ${ }^{11}$ Ischaemic macular oedema is known to occur in patients with retinal vein occlusions, in whom it has been postulated to be due to hyperosmotic effects within the retina; in this situation it appears to carry a good prognosis. ${ }^{12}$ The reasons for it in our patients are not readily apparent as it occurred in each of the three diagnostic groups: idiopathic, Behçet's and sarcoid. Retinal microvascular occlusion is relatively

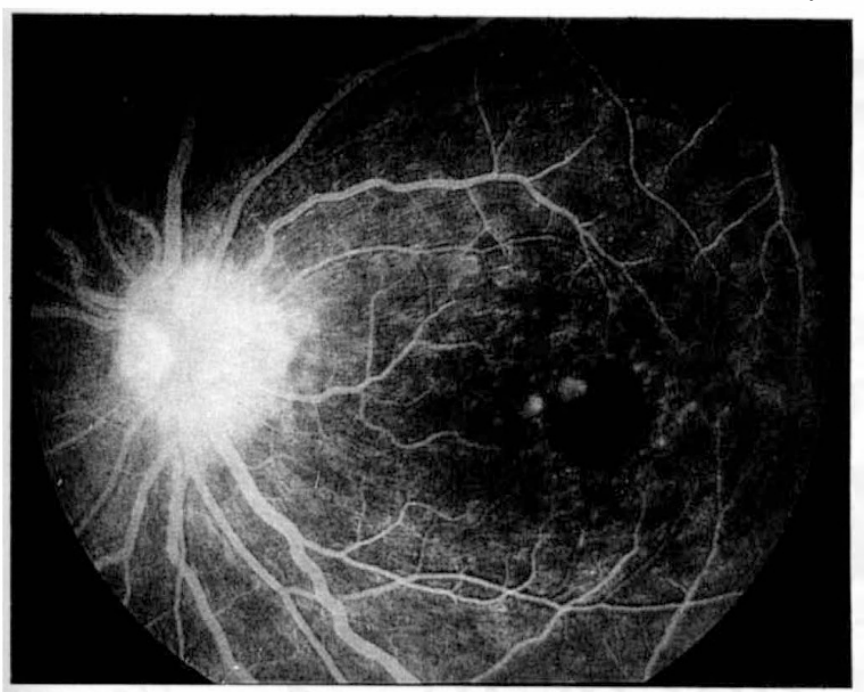

common in Behçet's disease, but this is usually of larger vessels than the perifoveal capillaries. ${ }^{5}$ Patients with Behçet's disease are known to have high fibrinogen levels, anti-cardiolipin antibodies and high viscosity in the active stage, ${ }^{13,14}$ but microvascular occlusion where there are no such aetiological clues has also been reported in both sarcoidosis and idiopathic retinal vasculitis. ${ }^{15}$ In our patients, haematological and clotting screens were normal apart from in 2 patients with slightly elevated antithrombin III levels. An increase in this protein is usually associated with increased fibrinolysis which is not compatible with the clinical picture, and was probably due to the concurrent use of systemic steroids by the patients.

This study has shown that some patients with posterior uveitis who failed to respond visually to full immunosuppression had macular ischaemia, even in the presence of CMO. We suggest that all patients with posterior uveitis should have a fluorescein angiogram before systemic treatment, when special attention should be given to the

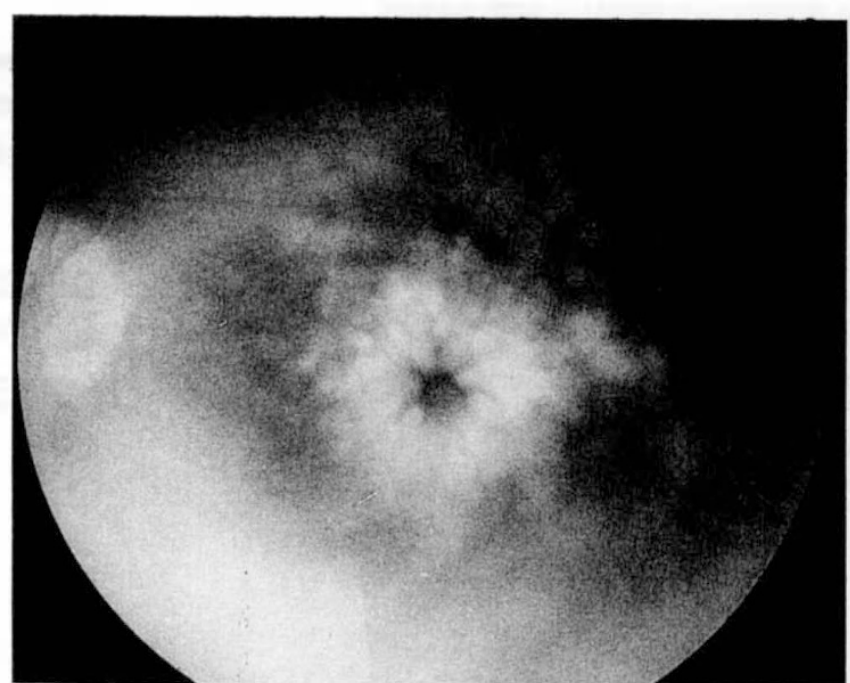

Fig. 3. Fluorescein angiogram of patient 11. Left: in the early phase, irregularity of the foveal avascular zone and perifoveal leakage. Right: in the late phase, the typical changes of cystoid macular oedema. 
early venous phase to detect signs of macular ischaemia. If visualisation is not sufficiently clear the angiogram should be repeated after or during treatment when the ocular media clears.

Full immunosuppression should be given to all patients at the start, but if macular ischaemia is demonstrated and the vision fails to improve, the rationale for treatment should be revised. Some patients may still require highdose treatment for either their systemic disease or to control frequent relapses of acute uveitis, but in many the dose of these toxic drugs may be reduced.

This work was supported by the Iris Fund for Prevention of Blindness. The authors thank Mr. R. Dewhirst for the preparation of the illustrations and Mrs. D. Embleton for typing the manuscript.

Key words: Ischaemia, Macula, Posterior uveitis.

\section{REFERENCES}

1. Nussenblatt RB, Palestine AG, Chan CC, Stevens G, Mellow SD, Green SB. Randomised, double-masked study of cyclosporine compared to prednisolone in the treat ment of endogenous uveitis. Am J Ophthalmol 1991;112:138-46.

2. Towler HMA, Cliffe AM, Whiting PH, Forrester JV. Low dose cyclosporin A therapy in chronic posterior uveitis. Eye 1989;3:282-7.

3. Binder AI, Graham EM, Sanders MD, Dinning W, James DG, Denman AM. Cyclosporin A in the treatment of severe Behçet's uveitis. Br J Rheumatol 1987;26:285-91.

4. Nussenblatt RB, Palestine AG, Chan CC. Cyclosporin A therapy in the treatment of intraocular inflammatory disease resistant to systemic corticosteroids and cytotoxic agents. Am J Ophthalmol 1983;96:275-82.
5. Benezra D, Cohen E. Treatment and visual prognosis in Behçet's disease. Br J Ophthalmol 1986;70:589-92.

6. de Vries J, Baarsma GS, Zaal MJW, Boen-Tan TN, Rothova A, Buitenhuis HJ, et al. Cyclosporin in the treatment of severe chronic idiopathic uveitis. $\mathrm{Br} \mathrm{J}$ Ophthalmol 1990;74:344-9.

7. Masuda K, Nakajima A, Urayama A, Nakae K, Kogure M, Inaba G. Double-masked trial of cyclosporin versus colchicine and long-term open study of cyclosporin in Behçet's disease. Lancet 1989;1:1093-5.

8. Muftuoglu AV, Pazarli H, Yurdakul S, Yazici H, Ulku BY, Tuzun Y, et al. Short-term cyclosporin A treatment of Behçet's disease. Br J Ophthalmol 1987;71:387-90.

9. Yazici H, Pazarli H, Bames CG, Tuzun Y, Ozyazgan Y, Silman A, et al. A controlled trial of azathioprine in Behçet's syndrome. N Engl J Med 1990;322:281-5.

10. Nussenblatt RB, Kaufman SC, Palestine AG, Avis MD, Ferris FL. Macular thickening and visual acuity. Ophthalmology 1987;94:1134-9.

11. Listhaus AD, Freeman WR. Fluorescein angiography in patients with posterior uveitis. Int Ophthalmol Clin 1990;30:297-308.

12. Finkelstein D. Ischaemic macular oedema.Invest Ophthalmol Vis Sci (ARVO Abstract) 1992;33:805.

13. Hull RG, Harris EN, Gharavi AE, Tincanig A, Asherson RA, Valesini G, et al. Anticardiolipin antibodies: occurrence in Behçet's syndrome. Ann Rheum Dis 1984;43:746-8.

14. Hampton KK, Chamberlain MA, Menon DK, Davies JA. Coagulation and fibrinolytic activity in Behçet's disease. Thromb Haemost 1991;66:242-94.

15. Graham EM, Stanford MR, Sanders MD, Kasp E, Dumonde DC. A point prevalence study of 150 patients with retinal vasculitis. I. Diagnostic value of ophthalmological features. Br J Ophthalmol 1989;73:714-21. 